expect to sec the same rainbow directly and by reflection. It is also reasonable to suppose that, as a rainbow is often seen from one place and not from another, a rainbow may often be scen directly and not reflected, or cici iersit. The reference to the necessury condition of parallelisn shows that it is something more than these obvious deduction. from the laws of reflection to which Prof. Tyndall wishes to ciras attention in the passage mentioned. Until I tried the cxperiment described below, I imagined him to mean that there was something about the direction or arrangement of the rays of light producing a rainbow, which prevented their forming a rainbow or anything like one, after reflection from the surface of still water. It is not always easy to arrange so as to have a rainbow and a still lake to experiment upon. I managed, however, to get satisfactory substitutes in the spray bow at the falls of the Khine near this, and a small pool of water. I was greatly disappointed on looking into my pool, to see reflected not only the scenery of the falls, but also a very fine spray bow.

What then can Prof. Tyndall mean? How is this peculiarity of rainbows to be observed? I have tried it in the only way of which I could think, but am now inclined to believe that I must have mistaken Prof. Tyndall's meaning.

Schaffhausen, Aug. 23

Z. X. Y.

\section{The Origin of Nerve Force}

ONz at least of the "obvious difficulties" which your corre. spondent, Mr. Henry R. Proctor, finds in my hypothesis as to the origin of Nerve Force, would scarcely have existed if he had directed his attention to a sentence in my article (NATURE, July 31 ), which runs thus: "In what are termed hot-blooded animals, that is, in mammals and birds, the difference of temperature between the surface and the interior is considerable under all natural circumstances, and in them there is a regulating action of the skin by which they maintain a uniform internal tempera. ture, always hotter than the surface, whatever that of the external medium may be." The correctness of this proposition as regards the human being is now a physiological fact, as many observers from different starting points have arrived at the same conclusion; among others, my proof of it has appeared in the "Journal of Anatomy and Physiology" (vol. vi. November $1 \delta 71$ ). When the temperature of the atmosphere is above $70^{\circ} \mathrm{F}$. the amount of perspiration is always proportiozate to the temperature, and is sufficient to maintain the depths of the body at $9 S^{\circ}$ or so. Below $70^{\circ}$ the same condition results from the infuence of coll on the cutaneous vessels, they contracting in proportion to the degree of cold, and so modifying the radiating and conducting power of the body surface. There is nerar therefore any reversal of the current, or a temperature at whic? it is nil.

Your correspondent's third paragraph contains an assumption, as great and not so reasonable as my oivn. Why should we have to assume that the body has to be kept at a constant temperature of $9 \mathrm{~S}^{\circ}$ or so? There is no a priori reason in its favour. It may be said that the chemical changes which occur, being dependent on the properties of albumen, fibrin, Sic., could not be continued under other circumstances. That, however, is only a shifting of the ground of argument, for it is much more reasonable to suppose that the properties of the animal tissues are the result and not the cause of the conditions under which they have been brought into existence.

I may mention that the physiological phenomena attending the immersion of the body in air and water of different temperatures are of quite a different character; they are scarcely comparable, and can be shown not to depend to any extent on the different conducting powers of the media, or their different specific heats. Immersion of the nude body in air of $30^{\circ}$ is not rapidly fatal, even if the temperature is not kept up by violent exercise; and I cannot understand "immersion in water at $30^{\circ}$."

If the comparative coldness of the brain were the effect of absorption of heat in the building up of its elaborate texture, we should expect to find a similar condition in the muscles, which are also of very complicate construction. Such, however, is not the case, and therefore ano:her explanation has to be found, which my hypothesis supplies.

Aug. 26

A. II. GARROD

The Flight of Birds

I IIAVE just read with great interest, in NATURE of Aug. 21, Capt. J. Herschel's account (elicited by Mr. Guthrie's letter, rol. viii. p. 86) of his ocular and tclescopic observations ot Indian kites at rest in mid-air, and I am tempted to offer an explanation which occurs to me of the way in which that aërial balance may be maintained.

If there was no quiver of the wings perceptible "at an appa. rent distance of ten or twelve feet,"-if the very tips of the wings "looked as steady as those of a stuffed specimen,"-then certainly the theory of self-support by muscular action must be abandoned, and the problem is reduced to one in which we have only to consider the weight and shape of the bird with outspread wings and the velocity and direction of the wind.

If the direction of the wind is slanting upwards with mode. rate velocity, it is conceivable that a bird, facing the wind, with outspread wings in a plane inclined between the horizontal and the direction of the wind, might remain at rest, from the following considerations :-

If the air were at rest, the bird, with the plane of its wings inclined a little downwards and forwards, would not fall vertically, but would slide obliquely forwards down the air, like a returning boomerang, or an inclined sheet of paper let fall, and would reach the earth at some point far from the vertical. But suppose, instead of the air being at rest, there were a slant upward current of air meeting and balancing the slant fall of the bird : then the bird would remain motionless in mid-air.

Capt. Herschel rejects (perhaps too hastily) the notion of "slants of wind," and asks "what becomes of the horizontal force" of the wind. Surely its effect would be to balance the horizontally resolved portion of the bird's slant fall, just as the vertically resolved portion of the slant current of wind would balance the vertically resolved portion of the slant fall.

Different degrces of inclination and force of the wind might be met (within limits) by different degrees of slope and spread of the wings.

I must confess this is only theory. We want more obser. vations, as keen and careful as Capt. Herschel's, to ascertain the force and direction of the wind attending this arrest of motion in mid-air. Slant currents are common enough on a small scale among house-walls, and on a larger scale we may see how the wind pounces down on a land-locked water, or presses up a mountain side. In a steady wind, the shapes of hill and valley must cause certain regular currents variously inclined to the horizontal, and some of these, I suppose, the eagles find and use. On the lee side of a hill (as in the case given by Captain Herschel) there would be a current rising trom the eddy to join the main course of the wind. The conditions described by Mr. Guthrie were just such as would throw the wind into upward slanting currents.

We should want a well-balanced weather-cock with a double vane (one plate in a horizontal, the other in a vertical plane), to tell the vertical as well as the horizontal deviation of the wind.

Dacre Park, Lee, S.E., Aug. 24 IIUDERT AIRY

\section{Mallet-Palmieri's "Vesuvius"}

My absence in Spain during the months of March and April prevented my having seen NATURE for the 20th March, and left me until a few days since in blissful ignorance that it contained a lengthy critique by Mrr. Mallet on my review (NATURE, Feb 6) of his translation of "Palmieri's "Inctndio Vesuviano." This accounts for my silence, as, had it not been the case, a reply from me would certainly have appeared at the time.

For, being "t the reviewer reviewed," I suppose I am indebted to my habit of not taking advantage of a reviewer's privilege, but of signing my name in full, "since I do not find that Mr. Mallet vouchsafed a reply to any other review of his book, not even to that contained in the Geological Mfagazine for March, which, as the organ of British Geological opinion, mlght be expected to have the preference over mine, even if its reviewer had not incurrea special claims on Mr. NIallet's attention, by having handled his production in a vastly less tender manncr than I had done.

In comparing the two translations of Palmieri's little pamphlet, I give preference to that in German by the eminent mineral chemist Rammelsberg, if for no other reasons, for its cheapness, and becuuse the translator puts forth the work of the Italian professor entirely on its own merits as one which did not require to be heralded by any elaborate preface to make it take with the publis, and also because it seems somewhat unfair to see the worthy I'rofessor's excellent observations made a vehicle for in. troducing the public to what, although entitled "an introduc. 